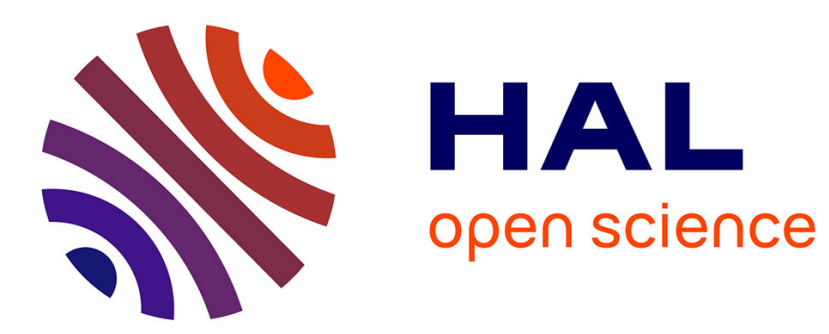

\title{
Rheological and crystallization behaviors of low processing temperature poly(aryl ether ketone)
}

Margot Bonmatin, France Chabert, Gérard Bernhart, Toufik Djilali

\section{To cite this version:}

Margot Bonmatin, France Chabert, Gérard Bernhart, Toufik Djilali. Rheological and crystallization behaviors of low processing temperature poly(aryl ether ketone). Journal of Applied Polymer Science, 2021, 138 (47), pp.51402. 10.1002/app.51402 . hal-03304519

\section{HAL Id: hal-03304519 https://imt-mines-albi.hal.science/hal-03304519}

Submitted on 9 Sep 2021

HAL is a multi-disciplinary open access archive for the deposit and dissemination of scientific research documents, whether they are published or not. The documents may come from teaching and research institutions in France or abroad, or from public or private research centers.
L'archive ouverte pluridisciplinaire HAL, est destinée au dépôt et à la diffusion de documents scientifiques de niveau recherche, publiés ou non, émanant des établissements d'enseignement et de recherche français ou étrangers, des laboratoires publics ou privés. 


\title{
Rheological and crystallization behaviors of low processing temperature poly(aryl ether ketone)
}

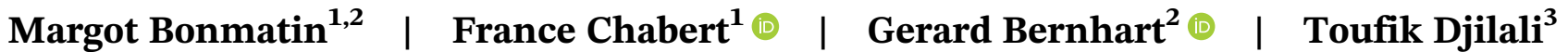

${ }^{1}$ ENIT-INPT, University of Toulouse,

Tarbes, France

${ }^{2}$ Institut Clément Ader (ICA), University of Toulouse, CNRS, IMT Mines Albi, INSA, ISAE-SUPAERO, UPS, Albi, France

${ }^{3}$ Groupe LAUAK, Research Department, Hasparren, France

Correspondence

France Chabert, ENIT-INPT, University of Toulouse, 47 Avenue Azereix, Tarbes, France.

Email: france.chabert@enit.fr

Funding information Victrex

\begin{abstract}
A new low melting temperature poly(aryl ether ketone) (PAEK) thermoplastic polymer (Victrex AE 250) was investigated through thermal and rheological analysis of films and flakes. DSC was assigned to evaluate the influence of cooling rate on crystallinity and thermal transitions. Rheometry was used to assess its flowing behavior through the evaluation of dynamic moduli and complex viscosity in the melted state. The relaxation times were found from the rheological curves: they are between a few ms to $200 \mathrm{~ms}$ for AE 250, lower than those found for PEEK 450, meaning a faster mobility of macromolecules. The thermal activation energy, $E_{\mathrm{a}}$ obtained from Time Temperature Superposition is the same for films and flakes in spite of a lower viscosity for flakes. The molecular weight between entanglements is evaluated at 8000 g.mol ${ }^{-1}$ for FMc and 13,000 for FLc, it is compared to the value of about $2000 \mathrm{~g} \cdot \mathrm{mol}^{-1}$ found for PEEK 450 with the same procedure. Also, the viscosity was compared to other commercial PAEK such as PEEK and PEKK based on data from the literature. This polymer appears very efficient to compete with high performance thermoplastics to be processed by compression molding, out of autoclave consolidation, additive manufacturing, and welding.
\end{abstract}

\section{KEYW O R D S}

crystallization, macromolecular structure, poly(aryl ether ketone), rheology, viscosity

\section{1 | INTRODUCTION}

The biggest challenge that the aerospace industry has to overcome is to reduce its environmental footprint. The Covid crisis can fast-track business transformation toward higher sustainability. One option is to lighten materials and structures by shifting to composites. Poly(aryl ether ketone) (PAEK) are high performance thermoplastic polymers. From their launch in the 80 's, they have been increasingly used in the aerospace industry, among which the manufacturing of carbon fiber reinforced composites. ${ }^{1}$ Their chemical structure is composed of benzene rings which bring mechanical strength, chemical and heat resistance, separated with either ether or ketone groups.
For about 10 years, the trend is the replacement of thermoset composites by thermoplastic composites in the aim of reducing manufacturing cost and environmental impact since thermoplastic polymers can be recycled unlike thermoset polymers. ${ }^{2}$ Fiber reinforced PAEK are processed by fast and well-known techniques ${ }^{3}$ such as compression molding or out of autoclave consolidation.

Among the PAEK family, PEEK poly(ether ether ketone) is by far the most used in the industry to find applications in automotive, aerospace, and healthcare sectors. $^{4-7}$ Indeed, PEEK exhibits high elastic modulus below its glass transition at $150^{\circ} \mathrm{C}$ and it can be used up to its melting temperature at $330^{\circ} \mathrm{C}$. In comparison to other semi-crystalline polymers, it also displays great 
chemical resistance to most solvents and severe conditions and its biocompatibility make it suitable to be used in biomedical applications. ${ }^{8}$ Its association with carbon fibers has made PEEK-based composites essential in the thermoplastic composite industry. PEEK was first developed by ICI in the late 70's but since the early 80's, PEEK from Victrex company has accounted for the majority of the world demand. PEEK is synthesized by a nucleophilic substitution from hydroquinone, fluorinated aromatic compound, and dry potassium carbonate reagents. It is obtained by a polycondensation process with a polar aprotic solvent such as diphenyl sulfone (DPS). ${ }^{9}$ Due to high production cost, PEEK is one of the most expensive thermoplastic materials. The synthesis is performed at high temperature (around $400^{\circ} \mathrm{C}$ ) requiring high power energy.

Poly(ether ketone ketone) (PEKK) is another polymer of the PAEK family that challenge the use of PEEK in the industry. It is mostly developed by the company Arkema and synthesized by a Friedel-Crafts polymerization. Various grades of PEKK exist, allowing a melting temperature ranging from 305 to $390^{\circ} \mathrm{C}$ depending on the terephthalic (T)/isophthalic (I) ratio. The T configuration matches a para position of the groups surrounding the benzene ring whereas the I configurations matches a meta position. The $\mathrm{T} / \mathrm{I}$ ratio has also an influence on the crystallinity and mechanical properties. ${ }^{10}$

Gardner et $\mathrm{al}^{11}$ has demonstrated the link between the ether/ketone ratio and the thermal transition temperatures of PEKK. An increase of the ketone ratio implies a linear increase of the melting temperature and, to a lesser extent, a linear increase of the glass transition. ${ }^{11}$ PEKK with a T/I ratio of 1 is the PAEK that exhibits the highest melting and glass temperatures. Nonetheless, the author has mentioned that by varying the $\mathrm{T} / \mathrm{I}$ ratio, the values of the melting temperature decrease while maintaining the high glass transition temperature of the PEKK 100\% terephthalic. It was assumed that the decrease in the melting temperature is due to the formation of configurational defects when terephthalic conformation is replaced by isophthalic conformation. Therefore, those grades of PEKK do not follow the same laws of thermal transition variation as usual PAEKs.

Lately, Victrex has elaborated a new PAEK named Victrex PAEK AE 250. It is an innovative material that promises a lower melting temperature (around $300^{\circ} \mathrm{C}$ ) while maintaining a glass transition and mechanical properties similar to PEEK. Current PAEK have high glass temperature associated with high melting temperature. For instance, $T_{\mathrm{g}}=150^{\circ} \mathrm{C}$ and $T_{\mathrm{m}}=340^{\circ} \mathrm{C}$ for PEEK 450G, which is the most industrially used PAEK. PEK, PEKK, and PEKEKK exhibit high $T_{\mathrm{g}}$ but also have a higher $T_{\mathrm{m}}$. There is a relationship between $T_{\mathrm{g}}$ and $T_{\mathrm{m}}$ for

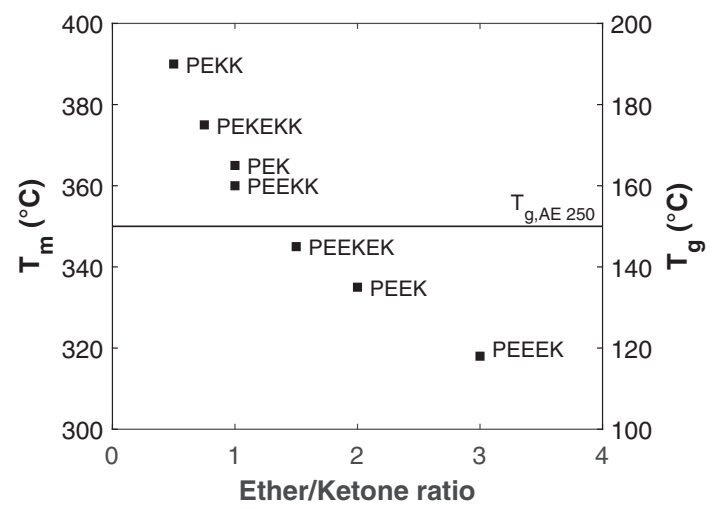

F I G U RE 1 Melting and glass temperatures of usual PAEK polymers as a function of the ether/ketone ratio (from Friedrich et al. ${ }^{14}$ )

all PAEK, as their transitions are plotted on Figure 1 below according to the ether/ketone ratio. Increasing $T_{\mathrm{g}}$ means extending the thermal stability and therefore the operating temperature range, since these types of polymers are often used below $T_{\mathrm{g}}$ to benefit their high mechanical strength. The polymer manufacturers target to increase $T_{\mathrm{g}}$. However, until now, increasing $T_{\mathrm{g}}$ of PAEK was paired with increasing $T_{\mathrm{m}}$. Yet, high melting temperature brings specific hardships and challenges to be faced: the processing temperature is above $T_{\mathrm{m}}$ whatever the techniques: injection molding, extrusion, or additive manufacturing. In the latter, many studies report that defects such as delamination and distortion are caused by thermal gradient across the part when printing by Fused Deposition Modeling (also called Fused Filament Fabrication): large internal stress, warpage, and delamination stem from a large temperature change during forming according to $\mathrm{Hu} .{ }^{12}$ Arif et al. ${ }^{13}$ reports delamination and poor mechanical performance for PEEK specimens built vertically, still due to high thermal gradient in the build-direction. Moreover, the high processing temperature of PEEK ( 350 to $430^{\circ} \mathrm{C}$ ) associated with high viscosity restricts the machines available to process this polymer whatever the processing technique. So, a new grade of PAEK combining high $T_{\mathrm{g}}$ and lower $T_{\mathrm{m}}$ is a great achievement. PAEK AE250 fit this requirement with $T_{\mathrm{g}}=150^{\circ} \mathrm{C}$ and $T_{\mathrm{m}}=300^{\circ} \mathrm{C}$. So that the relationship between $T_{\mathrm{g}}$ and $T_{\mathrm{m}}$ is not valid anymore for this new grade.

As it can be seen in Figure 1, glass and melting transitions of PAEKs depend on each other following a variation relying on the ether/ketone ratio. ${ }^{14} \mathrm{~A}$ decrease of the ether/ketone ratio implies an increase of both glass and melting temperature. However, PAEK AE 250 does not follow usual behavior of PAEK polymers. It cannot be put into the graph since its melting temperature is 
around $300^{\circ} \mathrm{C}$ while its glass temperature remains around $150^{\circ} \mathrm{C}$. This new generation polymer is attractive because it can be processed at a temperature lower than usual PAEKs. Nevertheless, few information is available about its chemical composition and properties due to its novelty. The only study about the properties of PAEK AE 250 is by Audoit et al, ${ }^{15}$ who used differential scanning analysis (DSC), thermal conductivity measurements, dynamical mechanical analysis (DMA), and dynamic dielectric analysis to characterize it. It was confirmed that PAEK has a melting temperature about $40^{\circ} \mathrm{C}$ lower than PEEK while maintaining a glass transition in the same range, at $150^{\circ} \mathrm{C}$. The authors also showed that this polymer has a crystallization rate lower than PEEK. They assume that the crystallization process is faster for $\mathrm{AE}$ 250 and that configurational defects are present in its structure. Moreover, it was pointed out that the difference between melting $\left(T_{\mathrm{m}}\right)$ and crystallization $\left(T_{\mathrm{c}}\right)$ temperatures was higher for PAEK AE 250, which led to an easier processability of PEAK AE 250. Finally, thermal, mechanical, and dielectrical properties of PAEK and PEEK are close to each other. Despite the relevance of this article, a deeper insight about its flowing behavior in the melted state and its kinetics of crystallization are still needed before processing AE 250. Moreover, a quantitative comparison to existing PAEK would confirm the attractive potential of $\mathrm{AE} 250$ to compete with other PAEK for manufacturing of thermoplastic composites.

To this end, this study focuses on the evaluation of thermal and rheological behaviors of PAEK AE 250. First, isothermal conditions and dynamic heating ramps are conducted by DSC in order to get the kinetics of crystallization and by TGA to check the heat resistance. Then, dynamic rheological tests are carried out to evaluate the flowing behavior above the melting temperature, from which we access to relaxation times. The results are compared with other usual PAEKs such as PEEK and PEKK from data available in the literature. Thus, the PAEK polymer can be placed in respect to the other available products in the industry considering their properties.

\section{2 | EXPERIMENTS}

\section{1 | Materials}

PAEK AE 250 was supplied by Victrex as $60 \mu \mathrm{m}$ thick films (FM) and flakes (FL). FM were used as received for differential scanning calorimetry (DSC) and thermogravimetric (TGA) analyses. FM and FL were processed in a press at $350^{\circ} \mathrm{C}$ for $3 \mathrm{~min}$ in order to obtain $25 \mathrm{~mm}$ diameter disk-shape samples for rheometry, named respectively, FMc and FLc. All samples (FX and FXc) were dried at $150^{\circ} \mathrm{C}$ in an oven for $4 \mathrm{~h}$ before being used in any experimental procedures. PEEK 450G from Victrex was also supplied by Victrex and dried in an oven at $120^{\circ} \mathrm{C}$ for $24 \mathrm{~h}$.

\section{2 | Characterization}

\subsection{1 | Thermogravimetric analysis}

The evolution of dried FM under high temperature conditions is evaluated through isothermal experiments at 320 and $350^{\circ} \mathrm{C}$ on a TGA 2 Mettler Toledo device. In both cases, the tests are performed under nitrogen and oxygen atmospheres at $50 \mathrm{ml} . \mathrm{min}^{-1}$ for $2 \mathrm{~h}$. Encapsulated samples are between 5 and $15 \mathrm{mg}$-weight.

\subsection{2 | Differential scanning calorimetry}

The effect of cooling rate on thermal transitions and enthalpy are determined using a Perkin Elmer Differential Scanning Calorimeter 8000 . After heating at $360^{\circ} \mathrm{C}$ to cancel the thermomechanical history, cooling rates at $2,5,10,20,50,100^{\circ} \mathrm{C} \cdot \mathrm{min}^{-1}$ are applied under a nitrogen flow rate of $20 \mathrm{ml} . \mathrm{min}^{-1}$ until reaching the glass transition temperature. The aim is to compare the structure of FM, FL, and FLc without taking into account their processing conditions. Finally, a second heating at $20^{\circ} \mathrm{C}$. $\mathrm{min}^{-1}$ is undertaken from 80 to $360^{\circ} \mathrm{C}$ to measure thermal transitions and enthalpies at different cooling conditions. Each test is repeated at least 3 times. Crystallinity, $\chi_{c}$, is determined using the following Equation 1:

$$
\chi_{c}=\frac{\Delta H_{m}-\Delta H_{c}}{\Delta H_{\infty}}
$$

where $\Delta H_{m}$ and $\Delta H_{c}$ are the melting and cold crystallization enthalpies. $\Delta H_{\infty}$ is the theoretical enthalpy if the polymer was completely crystalline. The value is not available for the polymer of this study. Therefore, the value of PEEK, $\Delta H_{\infty}=130 \mathrm{J.g}^{-1}$ was used. This adds uncertainty in the determination of $\chi_{c}$ but other authors ${ }^{15}$ have chosen this method as well.

\subsection{3 | Rheometry}

Rheological behavior was investigated using a HAAKE MARS Rheometer by Thermofisher. The experiments are carried out using a $25 \mathrm{~mm}$ diameter parallel-plate configuration with a $2 \mathrm{~mm}$ gap under argon atmosphere. 
Initially, dynamic strain sweeps were performed to determine the linear viscoelastic regime (LVR).

Time sweep have been performed to check the thermal stability of the polymer along the experiment. The curves are provided as supporting information (Figure S1). The complex viscosity slowly increases with time. At $330^{\circ} \mathrm{C}, \eta^{*}$ goes from 1600 to 1750 Pa.s, an increase of $9 \%$. At $390^{\circ} \mathrm{C}, \eta^{*}$ goes from 750 to $900 \mathrm{~Pa}$.s, an increase of $20 \%$. The time sweeps confirm that structural changes occur during the experiments, but the authors assume these changes are small enough to not influence nor our analysis neither conclusive remarks. Indeed, the values in the terminal regime are not considered for calculation of the relaxation times: The $\mathrm{G}^{\prime}$ and $\mathrm{G}^{\prime \prime}$ are extrapolated from the curves at higher frequencies, meaning the 10 first minutes of the frequency sweeps. Dynamic frequency sweeps are then performed in order to quantify the conservative and loss moduli, G' and G", from which we calculate the complex viscosity $\eta^{*}$. The complex viscosity is given by the following equation, with $\omega$ the angular frequency:

$$
\left|\eta^{*}\right|=\frac{\sqrt{G^{2}+G^{\prime 2}}}{\omega}
$$

Conservative and loss viscosity, real and imaginary component of the complex viscosity, respectively $\eta$ and $\eta$, depend on complex moduli and angular frequency according to:

$$
\begin{aligned}
& \eta^{\prime}=\frac{G^{\prime \prime}}{\omega} \\
& \eta^{\prime \prime}=\frac{G^{\prime}}{\omega}
\end{aligned}
$$

The experiments are conducted as a function of the frequency $f$, which depends on the angular frequency of a factor $2 \pi, w=2 \pi f$. A dynamic test at $\omega$ is equivalent to a transient experiment for a duration $t=1 / \omega$ according to the Cox-Merck principle. ${ }^{16}$ Thus, the relaxation times are given as the inverse of the $\omega$ values.

\section{3 | RESULTS \& DISCUSSION}

\section{1 | Thermal stability}

Poly(aryl ether ketone)s are sensitive to thermo-oxidative environments. Indeed, the atmosphere condition affects the material response, especially in the melting state. ${ }^{17}$ Moreover, Day et al ${ }^{17,18}$ has shown the leading decomposition mechanism of PEEK starts with the molecular chain scission of the ether bonds. It is followed by the hydrogen abstraction of the neighboring polymeric chains, which leads to stable phenolic end groups. The reaction ends with the cleavage of the latter. It implicates the creation of chemical species, which are able to form phenol, the major product from pyrolyse reaction. The degradation of PAEK initially induces viscosity increase followed by a weight loss. Thus, it is necessary to evaluate the thermal stability considering the weight loss in a range of temperatures that will be used for processing $\mathrm{AE}$ 250 and for the following tests. Figure $2 \mathrm{a}$ shows the weight variation of FM for two isothermal conditions: 320 and $350^{\circ} \mathrm{C}$ under inert and oxidizing atmospheres for $2 \mathrm{~h}$. From the four curves, it is established that the atmosphere has a very little influence on the weight loss of $\mathrm{AE}$ 250 after $2 \mathrm{~h}$. At $320^{\circ} \mathrm{C}$, the weight loss is considered insignificant. At $350^{\circ} \mathrm{C}$, there is a slight difference (lower than $0.2 \%$ ) of the weight loss between air and nitrogen atmosphere testing. Furthermore, for each test, the weight loss is never higher than $0.6 \%$. The agreement of weight loss degradation states that there is a degradation
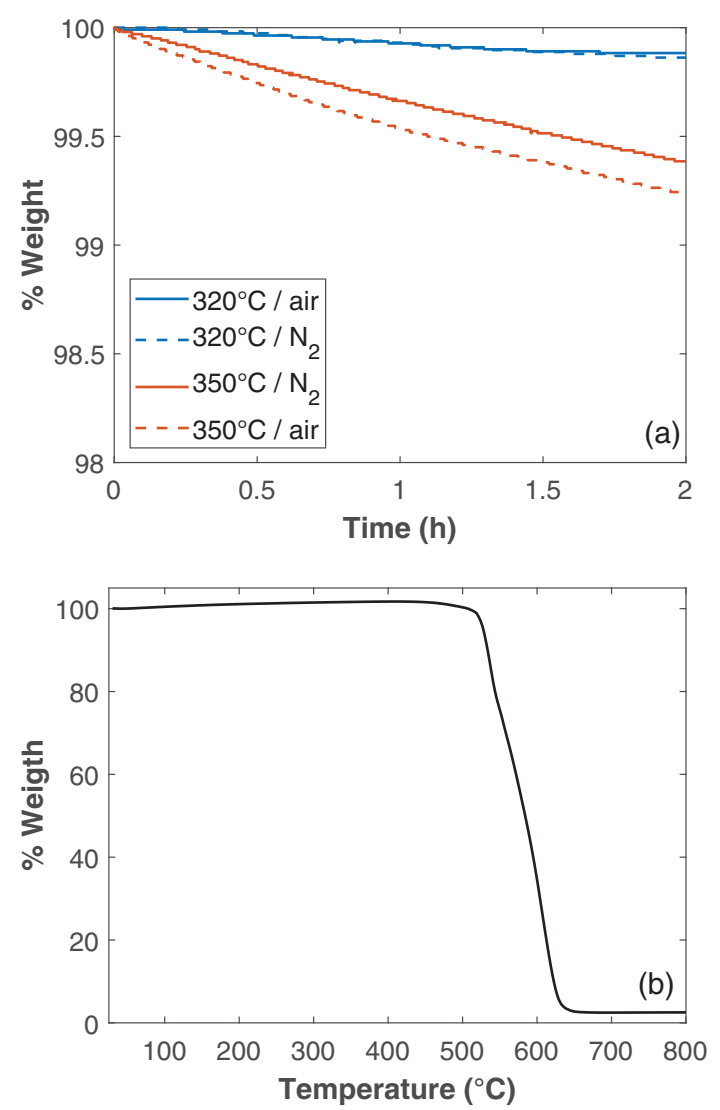

F I G URE 2 TGA curves of PAEK FM at two isothermal conditions ( 320 and $350^{\circ} \mathrm{C}$ ) under inert $\left(\mathrm{N}_{2}\right)$ and oxidizing (air) atmospheres (a) \& dynamical TGA curves of FM from 30 to $800^{\circ} \mathrm{C}$ at $2^{\circ}$ C.min ${ }^{-1}$ in an inert atmosphere (b) [Color figure can be viewed at wileyonlinelibrary.com] 
for a weight loss above 5\%. Therefore, it is considered that there is no weight loss degradation, no matter the atmospheric conditions. Nevertheless, the absence of structural changes is not excluded, as other techniques could reveal a degradation occurring by cross-linking and molecular re-organization without weight loss, such as rheometry for example. ${ }^{19,20}$ To go further, Figure $2 \mathrm{~b}$ presents the weight variation for a dynamical test between 30 and $800^{\circ} \mathrm{C}$ at $2^{\circ} \mathrm{C} \cdot \mathrm{min}^{-1}$. It indicates that the degradation, considered when the weight loss is $5 \%$ starts at $573^{\circ} \mathrm{C}$ for this test condition. Shabaev et $\mathrm{al}^{21}$ demonstrated that the degradation of PEEK starts at around $550^{\circ} \mathrm{C}$, wether it is under air or inert atmosphere. The stability of AE 250 is thus similar to PEEK. Finally, the stability shown in Figure 2 approves the use of $\mathrm{AE}$ 250 for further experiments at temperatures between 300 and $400^{\circ} \mathrm{C}$ for a few minutes.

\section{2 | Effect of cooling rate on thermal transitions and enthalpy}

Crystallinity rate and thermal transitions have a strong impact on the mechanical properties of a polymer. As an illustration, the Young's modulus of amorphous PEEK is $2 \mathrm{GPa}$ whereas those of PEEK that reached its maximum crystallinity (around $40 \%$ ) is $3 \mathrm{GPa}$ with a change in maximum strain at break. ${ }^{22}$ PEEK is known for its high melting temperature of $343^{\circ} \mathrm{C}$, which requires specific equipments for processing it and, therefore, a significant amount of energy input. This is why this new PAEK polymer is of great interest, it could facilitate the processing due to its lower melting temperature. In this section, the thermal behavior of FM, FL, and FLc were studied via DSC analysis. As a reminder, FM and FL are the dried PAEK used as received whereas FLc undergone hot press cycles, which could affect the polymer structure, and thus its properties. Figure 3 shows the first heating of the DSC analysis for the three shapes of samples. For each shape, the experiment was conducted at least 4 times. FM displays a glass transition at $157^{\circ} \mathrm{C}$, a cold crystallization temperature at $220^{\circ} \mathrm{C}$ and a melting temperature at $300^{\circ} \mathrm{C}$ with smooth results. The cold crystallization is probably due to the fast cooling during the filmmaking process, which led to an amorphous polymer. On the contrary, the curve of FL presents some discrepancies, especially with the presence of small peaks all over the temperature range. As a result of the wide range of sizes and shapes in the same batch of flakes, the contact area of the sample within the pan can change during the DSC measurements, especially when the polymer melts. Even before melting, the flakes can move when heated, affecting the data, and altering the straightness of the curve.

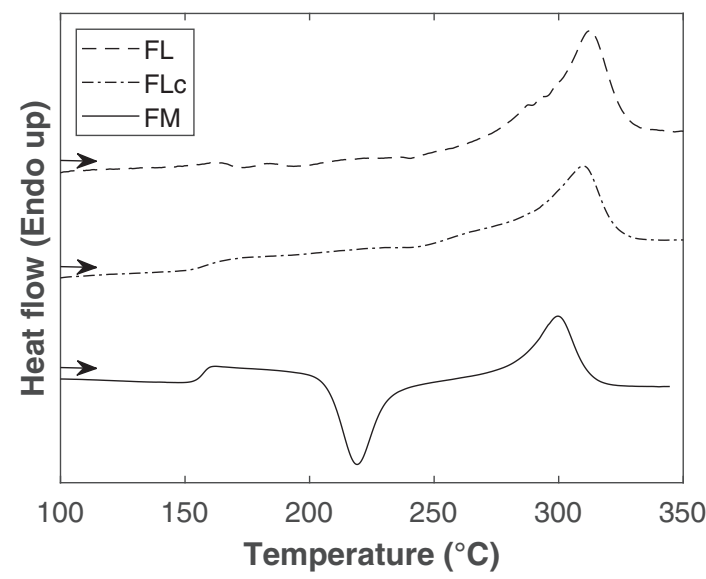

F I G U RE 3 DSC curves of FM, FL, and FLc for heating rate of $20^{\circ} \mathrm{C} \cdot \mathrm{min}^{-1}$

FLc first heating curve shows nonetheless less discrepancy than FL which implies that the compaction has a positive effect on DSC thermograms. The curves are more accurate and exhibit less undesired variations. Despite the irregulary of the curves, the average of the melting temperature and enthalpies were calculated and presented in the following (Table 1). Melting temperatures of FM, FL and FLc are lower than PEEK which improves the processability of AE 250 compared to PEEK, while maintaining a glass temperature in a similar range $\left(T_{\mathrm{g}}[\mathrm{PEEK}]=143^{\circ} \mathrm{C}\right)$. The melting and crystallization temperatures correspond to the maximum of the peaks. The melting temperature of flakes (FL and FLc) is higher compared to those of films of about $10^{\circ} \mathrm{C}$. This difference could be explained by the incorporation of small amount of additives in the formulation, the latter hinder ou facilitate the crystallization by changing of the free volume within the polymeric chains. Another hypothesis is the difference in molecular weights, polydispersity, and chemical structure. The flakes do not show a cold crystallization, it is due to their processing: they have been slowly cooled down to allow the polymer to crystallize at most. Still in the case of flakes, the glass transition is not visible and, therefore, it is not reported in the Table. It can also be seen from the Table 1 that FL has a crystallinity higher, at $25 \%$, than compressed flakes at $19 \%$. An assumption is that the samples were cooled too fast during the elaboration of our samples by compression molding. Finally, FM, FL, and FLc feature a melting temperature significantly lower than PEEK 450G, about $40^{\circ} \mathrm{C}$, while keeping a glass transition in the same range. These results have a positive influence on the processing of PAEK AE 250 since it can be formed at lower temperatures while maintaining a glass temperature similar to PEEK. 


\begin{tabular}{|c|c|c|c|c|c|c|}
\hline & $T_{\mathrm{g}}\left({ }^{\circ} \mathrm{C}\right)$ & $T_{\text {cc }}\left({ }^{\circ} \mathbf{C}\right)$ & $T_{\mathrm{m}}\left({ }^{\circ} \mathrm{C}\right)$ & $\Delta H_{\mathrm{cc}}\left(\mathrm{J} \cdot \mathrm{g}^{-1}\right)$ & $\Delta H_{\mathrm{f}}\left(\mathrm{J} . \mathrm{g}^{-1}\right)$ & $\chi_{c}(\%)$ \\
\hline $\mathrm{FM}$ & 157 & 220 & 300 & $-22.74 \pm 1.75$ & $21.99 \pm 2.14$ & $0.58 \pm 0.5$ \\
\hline FL & - & - & $312 \pm 2$ & - & $32.65 \pm 3.52$ & $25 \pm 2$ \\
\hline FLc & $155 \pm 2$ & - & $308 \pm 1$ & - & $24.82 \pm 1.79$ & $19 \pm 1$ \\
\hline
\end{tabular}

T A B L E 1 Average thermal transitions and enthalpies for FM and FL and FLc

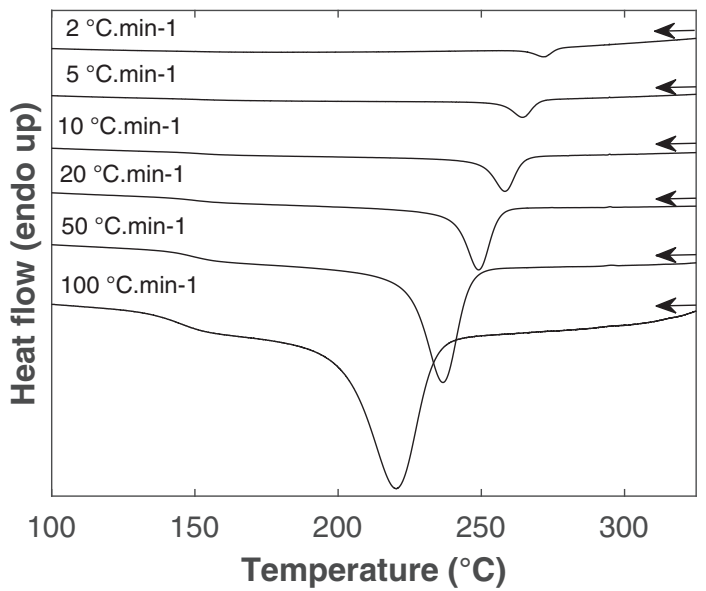

F I G U RE 4 DSC curves of FM for different cooling rates (2, 5, $10,20,50,100^{\circ} \mathrm{C} \cdot \mathrm{min}^{-1}$ )

Figure 4 shows the cooling curves of FM. As expected, the crystallization is shifted towards lower temperatures when the cooling rate increases. The same trend is noticeable for FL and FLc, thus, the curves are not presented in this article. This delay stems from both the inertia necessary for the chains to crystallize and the low thermal conductivity of the polymers. Moreover, the crystallization rate depends on the cooling rate, explaining why the area under the peak seems smaller when the cooling rate decreased. However, the cooling speed is taken into account for the calculation of the enthalpy. Crystallization and melting DSC peaks are associated with a population of crystallites with their own thickness. ${ }^{23}$ Figure 4 reveals crystallization peaks corresponding to large lamellae. The second heating of the same samples are presented for FM in Figure 5. From the second heating, the enthalpies and melting temperatures were calculated to evaluate the influence of cooling rate. Indeed, the DSC device is not calibrated on cooling, so the crystallization enthalpy is not reliable. The enthalpy must be evaluated from heating only that is why a following heating run was carried out right after. For PEEK, an annealing or slow crystallization is necessary in order to allow the entire crystalline phase to crytallize. ${ }^{24}$ It can be seen that a second crystalline peak appears at low cooling rate (from 20 to $2^{\circ} \mathrm{C} \cdot \mathrm{min}^{-1}$ ). The origin of this double-melting behavior is controversial and has been explained with different interpretations. ${ }^{25}$ An explanation could be the apparition of a second

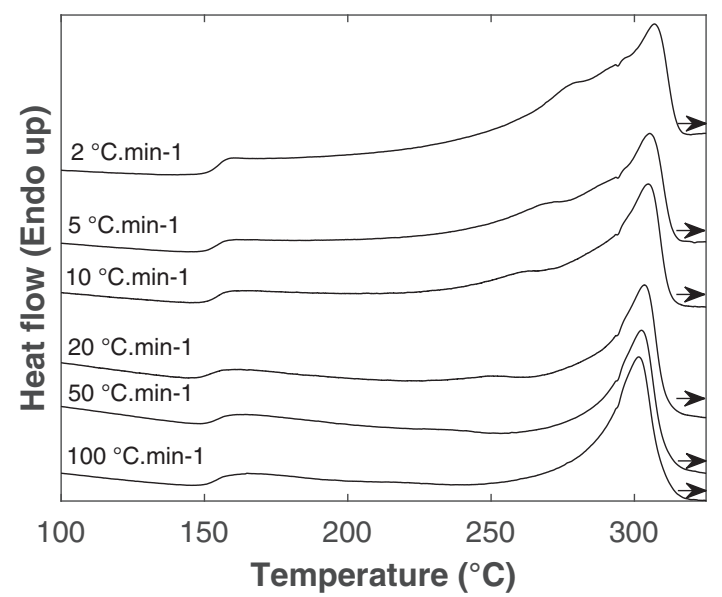

F I G U RE 5 DSC curves of the second heating of FM

crystalline phase, as suggested by Ko et al, ${ }^{24}$ implying that the morphology of AE 250 must be similar to the one of PEEK. The primary crystallization of PEEK is really fast, around few seconds whereas the secondary crystallization is a phenomenon that can last several hours. This is why this second crystalline peak becomes more intense at slow cooling rate.

Finally, melting enthalpies from the second heating were assessed and the crystallinities are presented in Figure 6a. As expected for all samples, the highest crystallinities are obtained at low cooling speeds. A low cooling rate allows a longer time for the macromolecular chains to self-organize into an ordered phase. The crystallinity of PEEK for a cooling rate of $30^{\circ} \mathrm{C} . \mathrm{min}^{-1}$ is $33 \%$, which is higher than $\mathrm{AE} 250$ at any cooling rate. Also, a slight decrease of the crystallinity from 2 to $50^{\circ} \mathrm{C} \cdot \mathrm{min}^{-1}$ is noticed. After $50^{\circ} \mathrm{C} \cdot \mathrm{min}^{-1}$, the crystallinity tends to stabilize to a threshold. The DSC device used in this study has a limited cooling rate of $100^{\circ} \mathrm{C} \cdot \mathrm{min}^{-1}$, this explains why there is no higher cooling rate analyzed. If higher cooling rates were investigated, it can be assumed that the polymer could reach an amorphous state as it has been seen that FM is amorphous. However, this threshold is not observed for FL and FLc because of the large scattering of the results. This phenomenon is associated with the structure of flakes. They probably contain additives, which can alter the crystallization and contribute to the scattered results. However, the maximum crystallinity obtained is around $30 \%$. Due to fast crystallization, 

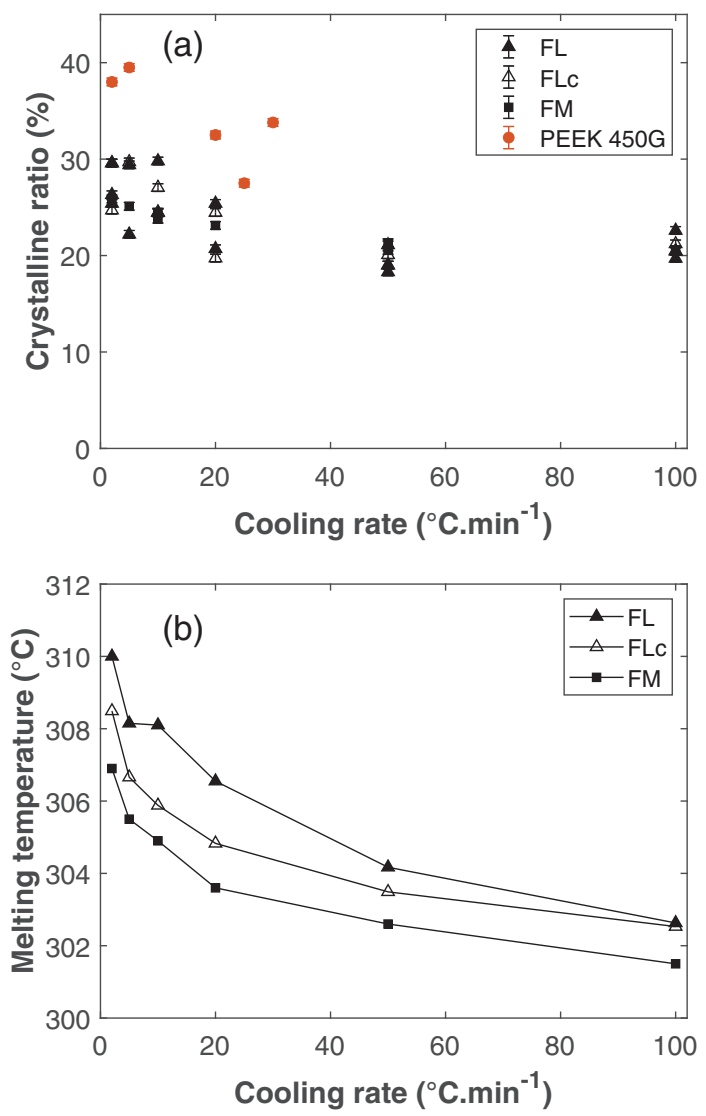

F I G U R E 6 Influence of cooling rate on crystallinity (a) and melting temperature (b) with an absolute incertainty of measurement of $2^{\circ} \mathrm{C}$ for the melting temperature [Color figure can be viewed at wileyonlinelibrary.com]

mastering the crystallization rate of PEEK is a hard task. When processing PEEK from the glassy state, it has been demonstrated that there are two levels of crystallization for PEEK 450G, identified as amorphous, or low level and a fully crystallized level. ${ }^{26}$ At the first level, referred as low one, the rate is around $15 \%$. The second level of crystallinity is around $35 \%$ from glassy state. Intermediate crystallization rates are difficult to get because of fast crystallization. Thus, mastering the properties of PEEK products is challenging. A slower crystallization such as in PAEK AE 250 is thereby of great interest. The crystallization can be more easily controlled and the polymer can be turned amorphous, such as FM, and thus transparent which is useful for some applications such as laser welding. Moreover, Martineau et al. $^{27}$ studied the autohesion of PEEK and brought to light the competition between the diffusion of the macromolecular chains and the crystallization growth during cooling. To create a strong bond between two surfaces, the chains need to diffuse at the interface and later crystallize. However, if the crystallization process is too fast, it hinders the mechanism of diffusion.
The second heating curves also point out the impact of cooling rate on melting temperature, as shown in Figure $6 \mathrm{~b}$. Only the melting point of the primary crystallization is taken into consideration for the Figure $6 \mathrm{~b} . T_{\mathrm{m}}$ decreases with the increase of the cooling rate for the three shapes. FM have the lowest melting temperatures in the entire range range of cooling rate and the highest ones are for FL as already outlined in the first heating curves.

\section{3 | Rheological characterization}

The rheological tests were performed in isothermal conditions, at temperatures chosen right after the end of the melting peak of $\mathrm{AE} 250$, while preventing its degradation at highest temperatures. All commercial PAEK are linear polymers as they are polymerized from bifunctional monomers. PAEK AE 250 is a linear polymer as described in the patent from Victrex (GB 2543362): "A polymer material, such as polyaryletherketone (PAEK) having a repeat unit of formula (I) -O-R1-O-R3- and a repeat unit of formula (II) O-R2-O-R3- wherein R1 and R2 are different". The patent lists all the possible monomers, they are all bifunctional ones. Moreover, the chemical reaction is explained as "polycondensation of two different di-hydroxy-containing compounds with one or more dihalogenated compounds". And these dihalogenated compounds are described as fluorine atoms, in the patent. It means that the condensation is a nucleophilic substitution, with the fluor attracting the labile $\mathrm{H}$ of the other monomer. The same reaction is carried out to synthetize PEEK from different monomers. This chemical reaction does lead to linear polymers.

Thus, to prevent the structural evolution, a new diskshape sample was step up on the plate of the rheometer for each experiment. For the same reason, the frequency sweeps start at $628 \mathrm{~s}^{-1}$ for which the point are recorded fast, up to the low frequencies. Each sample undergoes a fast temperature rise until reaching the targeted temperature $\left(330,350,370\right.$, or $\left.390^{\circ} \mathrm{C}\right)$. First, strain sweeps define the linear viscoelastic regime and characterize the strain dependent viscoelastic properties of the samples. G' and G" are respectively the conservative and loss moduli. The modulus $G^{\prime \prime}$ is always higher than $G^{\prime}$ in the studied domain, which indicates a liquid-like behavior as expected for molten polymers. G' and G" exhibit a pronounced nonlinear region at high strain amplitudes and tend towards a plateau at low strain amplitudes. Then, frequency sweeps from 6.28 to $62.8 \mathrm{~s}^{-1}$ were carried out. $\mathrm{G}^{\prime}$ and $\mathrm{G}^{\prime \prime}$ for each temperature are presented in Figure 7. Also, both moduli present a temperature dependency since they regularly decrease with an increase of temperature. According to the Rouse model, the moduli follow the rule of $\mathrm{G}^{\prime}=\mathrm{G} \omega^{2} \tau^{2}$ 

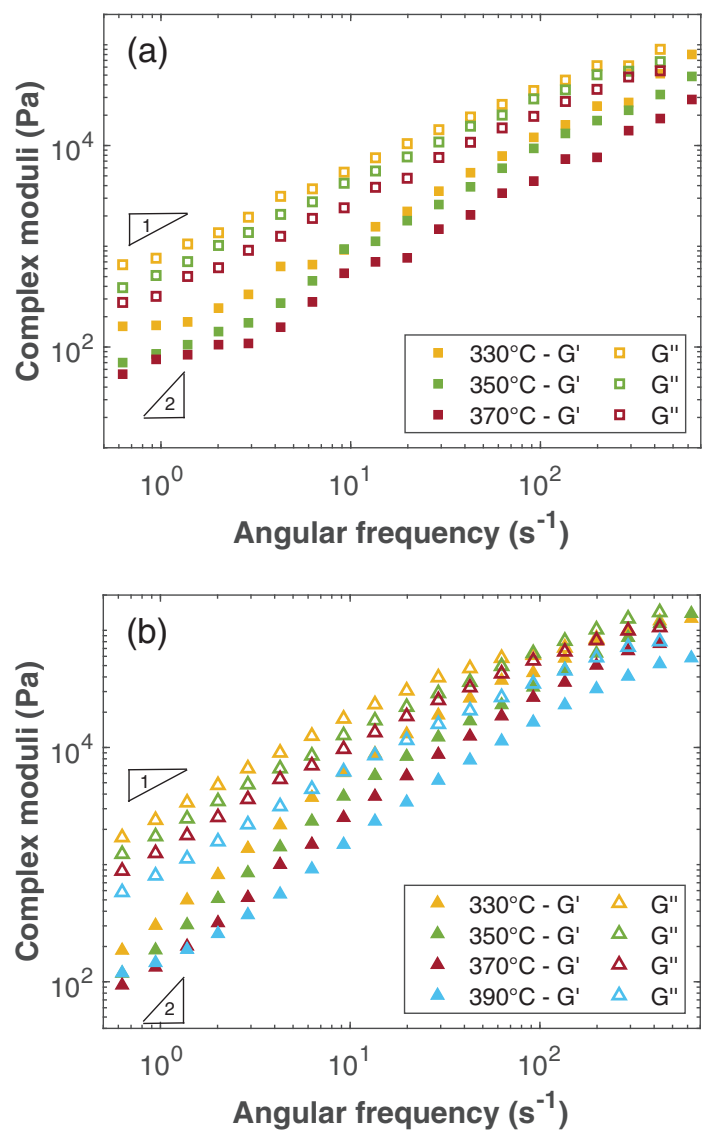

F I G U RE 7 G' and G" for FLc (a) and FMc (b) [Color figure can be viewed at wileyonlinelibrary.com]

and $\mathrm{G}^{\prime \prime}=\mathrm{G} \omega \tau$. So, the slope of $\log \mathrm{G}^{\prime}$ and $\log \mathrm{G}^{\prime \prime}$ are supposed to be of, respectively, 2 and 1 in the terminal region at low shear rate. As seen in Figure 7, the Rouse model fails as predicting the behavior in the terminal regime. Indeed, the angular frequency dependency is $\omega^{1.04}$ and $\omega^{0.92}$ respectively for G' and G" for FLc and $\omega^{1.11}$ and $\omega^{0.89}$ for FMc. Some data are available in the literature for PEEK grades only. For instance, a dependency of $\omega^{1.81}$ and $\omega^{0.99}$ is found by Bangarusampath et al. $^{28}$ for a Victrex PEEK 151. In Garcia-Leiner'work, ${ }^{29}$ the slopes are 1.54 and 0.91 for $G^{\prime}$ and $G$ " respectively for a PEEK Ketaspire KT-820NT and 1 and 0.75 for $G^{\prime}$ and $G "$ respectively for PEEK Victrex 450G. This deviation from the theoretical behavior is attributed to the evolution of the macromolecular structure during the experiment. Seo et al. ${ }^{30}$ displays the expected shapes of $G^{\prime}$ and $G^{\prime \prime}$ curves for PEEK $450 \mathrm{G}$ by using Time Temperature Superposition (TTS) on data obtained at higher frequencies for which the acquisition time at $350^{\circ} \mathrm{C}$ is shorter to prevent structural changes.

PAEK AE 250 has initially a linear structure evolving towards a partially cross-linked system. Indeed, all PAEK are sensitive to thermo-oxidative degradation due to their chemical structure. From the previous studies of Day ${ }^{18,31}$

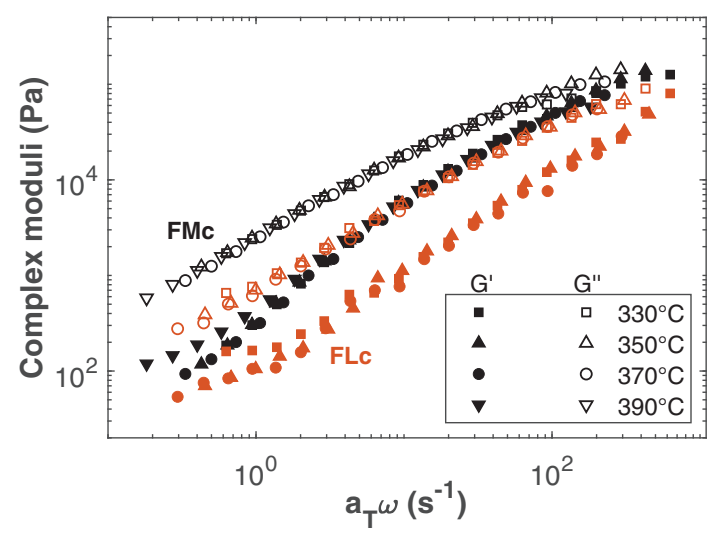

F I G U RE 8 Master curves of G' and G" for FLc and FMc with the reference temperature at $330^{\circ} \mathrm{C}$ [Color figure can be viewed at wileyonlinelibrary.com]

on the degradation mechanisms of PEEK, it is known that when PEEK is kept above $340^{\circ} \mathrm{C}$ in oxidative conditions, chain cleavage occurs adjacent to the carbonyl functional groups and subsequent hydrogen abstraction from the aromatic ring then leads to crosslinking between adjacent aryl rings. This recombination causes a color change, a dramatic increase of its shear viscosity and a reduction in the crystallizability of the material. The decomposition of this PAEK AE 250 has not been studied yet, but it could follow the same degradation mechanism, as its chemical structure is close to those of PEEK. The main concern is the cross-linking kinetics. From the time sweeps performed, it is clear that the cross-linking starts as soon as the polymer is exposed to temperature above its melting temperature.

Time Temperature Superposition (TTS) was applied on previous data and shift factors, $\mathrm{a}_{T}$, were identified from $G^{\prime}$ and $G^{\prime \prime}$ moduli, for each temperature by horizontally shifting their curves. Between 6.28 and $62.8 \mathrm{~s}^{-1}$, the time-temperature superposition gives good results, which confirms that this polymer follows more or less the expected behavior for melted polymers. However, below $6.28 \mathrm{~s}^{-1}$, it becomes harder to match the different curves, especially for FLc. When comparing both master curves obtained for FL and FM in Figure 8, the cross-over point is shifted towards low frequencies for FM, this indicates that the molecular weight for FM would be higher than those of FL. ${ }^{32}$

The complex viscosity $\eta^{*}$ is then deduced by the following equation depending on the angular frequency $\omega$ :

$$
\eta^{*}=\frac{\sqrt{G^{2}+G^{\prime \prime 2}}}{\omega}
$$

Master curves of the complex viscosities of FMc and FLc are displayed in Figure 9. They were calculated in 


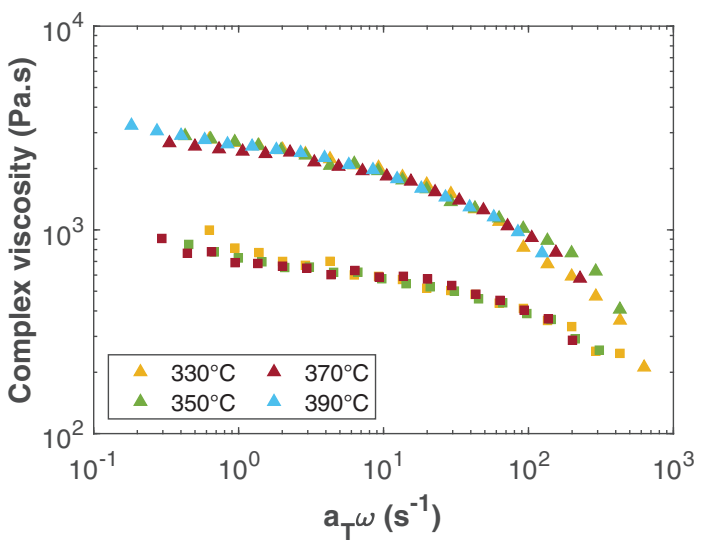

F I G U RE 9 Master curves of the complex viscosity for FLc $\left(-\square\right.$-) and FMc (- $\triangle-$ ) with the reference temperature at $330^{\circ} \mathrm{C}$ [Color figure can be viewed at wileyonlinelibrary.com]

both cases at a reference temperature of $330^{\circ} \mathrm{C}$. The curves exhibit a pseudo- Newtonian plateau in the range 0.628 to $62.8 \mathrm{~s}^{-1}$ and a shear-thinning region above $6.28 \mathrm{~s}^{-1}$, following the well-known flow curve for melted polymers. The complex viscosity at the plateau is called the zero-shear viscosity, $\eta_{0}$. The zero-shear viscosity strongly depends on molecular weight: above a critical mass noted Mc, the zero-shear viscosity depends linearly on molecular weight while above Mc, it is supposed to rise with $M^{3.4 .33}$ Again, the complex viscosity for FM is higher than those for FL. It corroborates the idea that the molecular weight is higher for FM compared to FL. In both cases, the complex viscosity slightly rises at the lowest angular frequencies. The behavior at low frequencies is not classical since a plateau would be extend up to the zero-shear viscosity. Again, this is attributed to the evolution of the structure upon cross-linking of chains during degradation ${ }^{18}$ as it was shown by Bakrani et al. ${ }^{34}$ in viscosity curves for PEEK 450G. This phenomenon could explain the divergence in the shifting at low frequencies and the fact that no weight loss was observed by TGA analysis, that is, a structural degradation without weight loss and possibly other phenomenons that are yet to be understood.

Shift factors of TTS are plotted in Figure 10 for FLc and FMc. The data agree with the Arrhenius law as following:

$$
\ln \left(a_{T}\right)=A-\frac{E_{a}}{R T}
$$

where $E_{a}$ is the activation energy, $\mathrm{R}$ is the gas constant, and $\mathrm{T}$ the temperature. The activation energies for FLc and FMc are, respectively, 61 and $66 \mathrm{~kJ} \cdot \mathrm{mol}^{-1}$. The values of $E_{a}$ are considered as identical regarding the

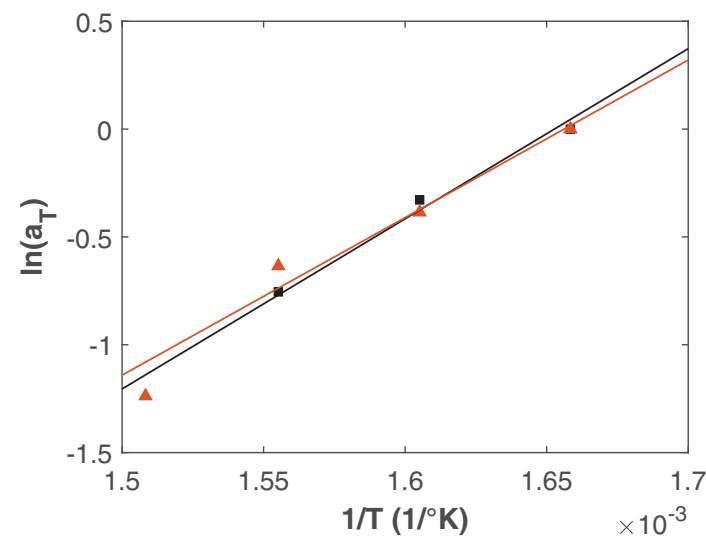

F I G U RE 10 Arrhenius graphe of the shift factor of FLc ( $-\square$-) and FMc $(-\triangle-)$ [Color figure can be viewed at wileyonlinelibrary.com]

T A B L E 2 Activation energy for usual industrial PAEKs

\begin{tabular}{|lc|} 
& $\boldsymbol{E}_{\mathbf{a}}\left(\mathbf{k J . m o l}{ }^{\mathbf{1}}\right)$ \\
\hline PEEK $151 G^{35}$ & 35 \\
PAEK AE 250 - (FLc) & 61 \\
PAEK AE 250 - (FMc) & 66 \\
PEEK $450 G^{36}$ & 90 \\
\hline PEKK $6003^{37}$ & 136 \\
PEKK $7003^{37}$ & 156 \\
\hline
\end{tabular}

uncertainty. The data found by other researchers are reported in Table 2. The activation energy of AE 250 is higher than $E_{a}$ for PEEK $151 \mathrm{G}$ and lower than $E_{a}$ for PEEK 450G and PEKK 6003 and PEKK 7003. This implies that $\mathrm{AE} 250$ requires less energy to melt than PEEK 450G and PEKK 6003 and PEKK 7003.

\subsection{Calculation of relaxation times}

To go further, the relaxation times are calculated from the frequency sweeps. Two average relaxation times are determined: $\tau_{w}$ is the mean relaxation time in the terminal region and $\tau_{n}$ is the mean relaxation time at the crossover point. These relaxation times are assigned as the reputation time, the time required by a polymeric chain to escape from its tube in the theory of De Gennes. ${ }^{38}$ These times are useful for any polymer processing when diffusion of chains is required such as welding, compression molding, or additive manufacturing. Indeed, the chains need to diffuse across an interface to reach the next polymeric part or the next layer, resulting in the creation of a bond. 


\subsection{1 | Definition of $\eta_{0}$}

The relaxation time $\tau_{w}$ depends on the zero-shear viscosity, $\eta_{0}$, and the steady-state compliance, $J_{e}^{0}$, as follow:

$$
\tau_{w}=J_{e}^{0} \eta_{0}
$$

As explained above, the determination of the zeroshear viscosity is tricky due to the evolution of the structure during the experiments at low frequencies. To circumvent this drawback, it is convenient to use the Cole-Cole representation. ${ }^{39}$

Figure 11 features the Cole-Cole plot, depicting the loss viscosity, $\eta^{\prime}$, as a function of the storage viscosity, $\eta^{\prime \prime}$ for FMc. The experimental data are supposed to follow a semi-circle equation and $\eta_{0}$ is the value when the semicircle is crossing the $\mathrm{x}$-axis in accordance with the equation given bellow:

$$
\eta_{0}=\sqrt{r^{2}-y_{c}^{2}}+x_{c}
$$

where $x_{c}$ and $y_{c}$ are the coordinates of the circle and $r$ is the radius. The model is plotted as a continuous line in Figure 11 and seems to be consistent with experimental data for each temperature. Experimental data at higher conservative viscosities show a deviation from the model, which can be explained by the evolution of the structure for the longest experiments.

\subsection{2 | Definition of $\mathrm{J}_{e}^{0}$}

The steady-state compliance $\mathrm{J}_{e}^{0}$ corresponds to the residual elasticity of the macromolecule due to the existence of an equilibrium conformation in coil chain under given

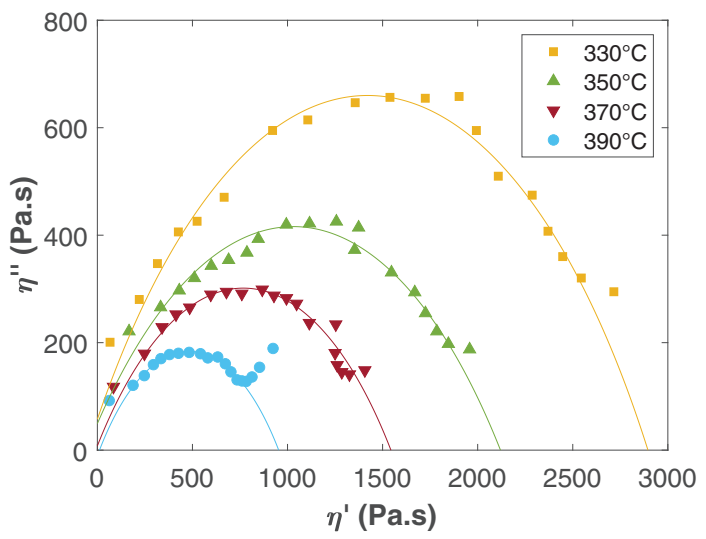

F I G U R E 11 Cole-Cole representation of the complex viscosity of FMc: $\eta^{\prime}=f\left(\eta^{\prime \prime}\right)$ for $330,350,370$, and $390^{\circ} \mathrm{C}$ [Color figure can be viewed at wileyonlinelibrary.com] temperature conditions. For melted polymers, $\mathrm{J}_{e}^{0}$ is obtained from the intercept of the lines with slopes 1 and 2 of the moduli $G^{\prime \prime}$ and $G^{\prime}$ respectively, at low frequencies. Since they do not reach this behavior, an extrapolation is made and the intercept of the tangents of the extrapolated curves is considered. $G^{\prime}$ and $G^{\prime \prime}$ at low frequency gives a value of modulus $G^{*}$ that follows the Equation 9:

$$
G^{*}=\frac{1}{J_{e}^{0}}
$$

The value of the steady-state compliance, $\mathrm{J}_{e}^{0}$, was calculated for each temperature condition. Then, the mean relaxation time $\tau_{w}$ is calculated with the Equation (7). $\tau_{w}$ is associated with the motion of the longest chains. The mean relaxation time $\tau_{n}$ is associated to the motion of the shortest chains. It corresponds to the inverse of the frequency obtained at the crossover point, meaning when $\mathrm{G}^{\prime}=\mathrm{G}^{\prime \prime}$. For instance, the cross-over at $350^{\circ} \mathrm{C}$ is at a frequency of $20 \mathrm{~Hz}$ so $\tau_{n}$ is $0.05 \mathrm{~s}$. The values of $\tau_{n}$ are presented in Table 3 with their corresponding modulus. These two methods of calculation are displayed in Figure 12 . The uncertainty of measurement is higher for $\tau_{w}$ due to the extrapolation. The relaxation times of the AE 250 polymer are shorter than those for PEEK, Figure 13. The chains of FLc and FMc need less time than PEEK 450G to start moving. The ratio $\tau_{w}$ over $\tau_{n}$ gives an indication of the polydispersity I of the materials. Figure 13 gives a representation of the width between $\tau_{w}$ and $\tau_{n}$ with temperature. FMc is more polydisperse than FLc since the ratio I is 76 for FMc and 22 pour FLc. This implies that the distribution of molecular weight, and hence the distribution of size of chains, is higher for FMc. As seen in Figure 13, the polydispersity of PEEK 450G is around 900 and it is higher than both PAEK AE 250. A greater value of I indicates that small and long chains of polymer coexist. The manufacturing such as injection and compression molding is therefore made more difficult since small chains will diffuse and degrade faster than longer chains. However, higher polydispersity can be interesting considering the assembly of

T A B LE 3 Cross-over values of the moduli for FLc and FMc

\begin{tabular}{|llllll} 
& FLc & \multicolumn{3}{l}{ FMc } \\
\cline { 2 - 3 } \cline { 5 - 6 } \cline { 5 - 6 } & $\mathbf{G}^{\prime}=\mathbf{G}^{\prime \prime}(\mathbf{p a})$ & $\boldsymbol{\tau}_{\boldsymbol{n}}(\mathbf{m s})$ & & $\mathbf{G}^{\prime}=\mathbf{G}^{\prime \prime}(\mathbf{p a})$ & $\boldsymbol{\tau}_{\boldsymbol{n}}(\mathbf{m s})$ \\
$330^{\circ} \mathrm{C}$ & 65,000 & 2 & 84,000 & 5 \\
$350^{\circ} \mathrm{C}$ & 46,000 & 1 & 125,000 & 2.7 \\
$370^{\circ} \mathrm{C}$ & 28,600 & 0.7 & 75,000 & 2 \\
$390^{\circ} \mathrm{C}$ & - & - & 56,000 & 1.7 \\
\hline
\end{tabular}




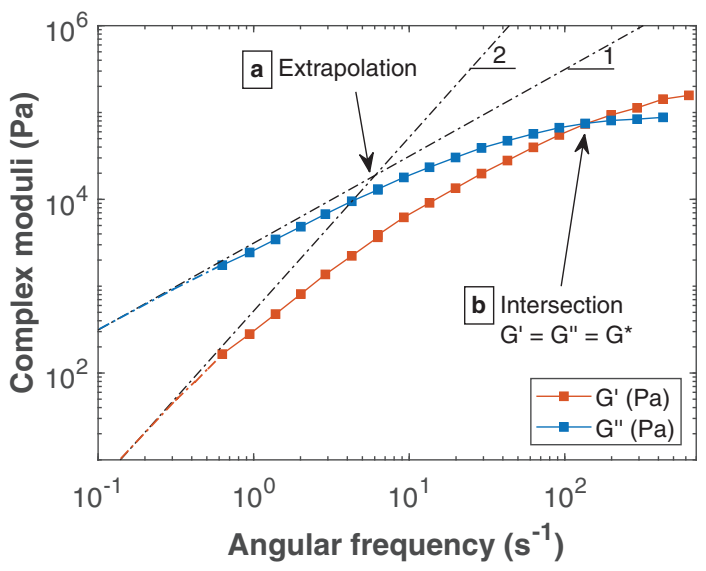

F I G URE 12 Complex moduli G' and G" of FMc at $330^{\circ} \mathrm{C}$ [Color figure can be viewed at wileyonlinelibrary.com]

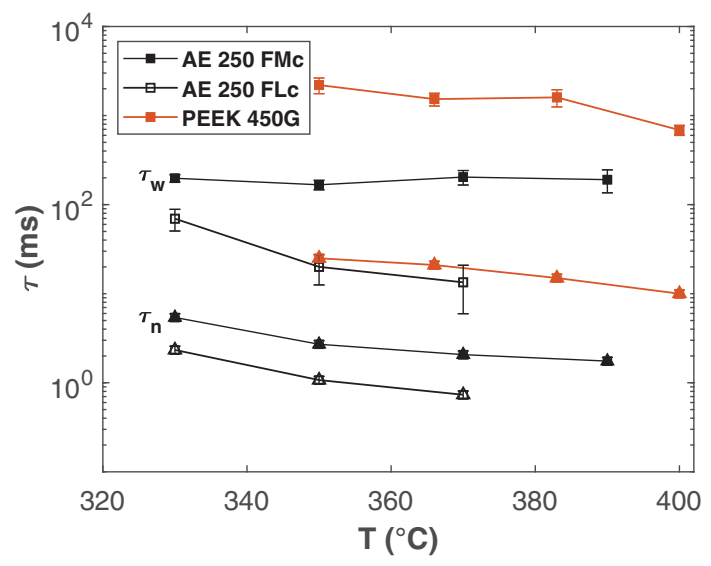

F I G U RE 13 Relaxation times, $\tau_{w}\left(-\square\right.$-) and $\tau_{n}(-\triangle-)$, of FMc, FLc, and PEEK 450G [Color figure can be viewed at wileyonlinelibrary.com]

two polymer parts since smaller chains will diffuse faster at the interface. Nevertheless, longer chains can entangle more easily and increase the elasticity of the material, which have a positive impact on the Young modulus.

\section{5 | Calculation of the molecular weight between entanglements}

The plateau modulus $G_{N}^{0}$ is related to the density of entanglements, noted $\nu$, by $G_{N}^{0}=\frac{4}{5} \nu k_{B} T^{40}$ The molecular weight between entanglements is obtained from:

$$
M_{e}=\frac{4}{5} \frac{\rho R T}{G_{N}^{0}}
$$

The plateau modulus $G_{N}^{0}$ is the value of $G^{\prime}(\omega)$ at the frequency where the minimum of the loss tangent $\tan \delta$

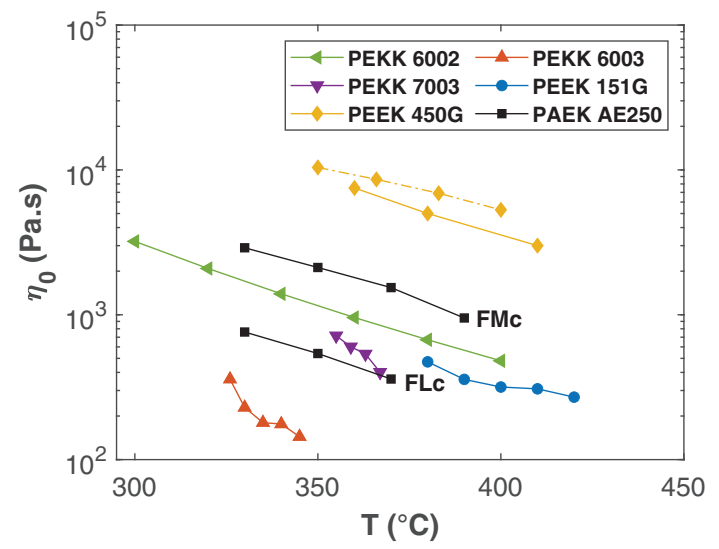

F I G U RE 14 Zero-shear viscosity with temperature for PEKK 6002, ${ }^{44}$ PEKK 6003, ${ }^{45}$ PEKK 7003, ${ }^{37}$ PEEK $151 \mathrm{G},{ }^{35}$ PEEK 450G,${ }^{34,46}$ and PAEK AE 250 [Color figure can be viewed at wileyonlinelibrary.com]

$\left(\tan \delta=\frac{G^{\prime \prime}}{G^{\prime}}\right)$ is located. It is possible to measure the plateau modulus for amorphous polymers by dynamic oscillatory tests. It becomes more tricky for semi-crystalline polymers, because it is impossible to measure $\mathrm{G}^{\prime}(\omega)$ and $\mathrm{G}^{\prime \prime}(\omega)$ at the plateau zone. A possibility to overcome this problem is the use of TTS. But, the frequency range of rheological measurements is comparatively small, due to the narrow temperature window between crystallization and degradation. Some attempts for predicting the value of $G_{N}^{0}$ from dynamic oscillatory measurements in the terminal region are proposed in the literature. $G_{N}^{0}$ is calculated from:

$$
G_{N}^{0} \approx \frac{\eta_{0}}{\tau_{n}}
$$

The molecular weight between entanglements is calculated with the previous data. $M_{\mathrm{e}}$ is about $2000 \mathrm{~g} \cdot \mathrm{mol}^{-1}$ for PEEK 450G which is consistent with the values found by Herrmann-Schronherr ${ }^{41}$ at 2100 g.mol $^{-1}$ and Roovers ${ }^{42}$ at $1300{\mathrm{~g} . \mathrm{mol}^{-1}}^{-1}$, the both from experiments at $350^{\circ} \mathrm{C}$. The values of $M_{\mathrm{e}}$ for FMc and FLc are respectively 8000 et 13,000 g. $\mathrm{mol}^{-1}$. The molecular weight between entanglements is unique for each polymer, it reflects the stiffness of the chemical structure. The higher is $M_{\mathrm{e}}$, the stiffer the structure is. So PEEK has the more flexible chemical structure, followed by FLc and FMc, which are the most rigid chains.

\section{6 | Comparison to other PAEK}

Finally, the zero-shear viscosity of AE 250 is compared to some commercial PEEK and PEKK in Figure 14. It can 
be seen the divergence of activation energies and temperature ranges. It can be noted that the viscosity of PEEK 450G, the most industrially used grade of PEEK, is higher than the material of this study and a lower viscosity implies an easier manufacturing. It is due to the fact the melting temperature of PEEK is about $40^{\circ}$ above Victrex AE 250 PAEK. PEKK 6002, PEKK 7003, and PEEK 151G show complex viscosity between FMc and FLc considering the value of $\eta_{0}$. Similarly, PEKK 6002 seems to possess a slope equivalent to FMc and FLc, which would suggest that the rheological behavior of Victrex $\mathrm{AE}$ 250 PAEK is close to PEKK 6002. As seen in Table 2, the activation energy of FMc and FLc are equivalent to the $E_{\mathrm{a}}$ of PEKK 6002 as noted in Figure 14. Activation energies of PEKKs 6003 and 7003 are higher due to the lower number of ether groups, which hinders the mobility of the polymer chains.

\section{4 | CONCLUSIONS}

This study gives a deeper knowledge of the crystallization and rheological properties of Victrex PAEK AE 250. This new polyaryletherketone has been recently launched with the promise of easier processing compared to other polyaryletherketones. The properties of PAEK AE 250 were investigated through the analysis of two shapes, films, and flakes. DSC analysis was performed in order to quantify the thermal transitions and enthalpies. The films initially exhibit an amorphous structure compared to flakes that have a crystallinity between $19 \%$ and $25 \%$. Therefore, cold crystallization will occur when the films are heated. As expected, the thermal transitions are delayed when the heating ramp or cooling ramp is faster. Also, the dependence of the crystallinity with the cooling ramp has been measured. From these results, it appears that the crystallization of AE 250 is slower than those of Victrex PEEK 450. Similar to the latter, a second crystalline phase was observed at low cooling rate, which increases the crystallinity up to $26 \%$ at most. The crystallization must be thoroughly controlled during the forming process because the mechanical properties strongly depend on the crystallinity.

Then, dynamic rheological tests were carried out to evaluate the flowing properties above the melting temperature. The rheological behavior of both PAEK AE 250 films and flakes looks similar to any melted polymer with a Newtonian plateau and a shear-thinning region, even is the data at low frequencies are not reached due to the evolution of the chemical structure with time. The shift of dynamic moduli fits the Time-Temperature Superposition, from which the aT coefficients show an Arrhenius-law dependency with an activation energy of
$60 \mathrm{~kJ} \cdot \mathrm{mol}^{-1}$. Then, two mean relaxation times were calculated: $\tau_{w}$ for the longest macromolecules in the terminal regime and $\tau_{n}$ for the shortest macromolecules at the cross-over point when $\mathrm{G}^{\prime}=\mathrm{G}^{\prime}$ '.

The relaxation times of $\mathrm{AE} 250$ are between a few $\mathrm{ms}$ to $200 \mathrm{~ms}$. They are lower than those found for PEEK 450 , meaning a faster mobility of macromolecules. Moreover, the relaxation times of the flakes are lower than those of films. The ratio of relaxation times gives an idea of the polydispersity. Both films and flakes demonstrate a sharper polydispersity than PEEK 450. Then, an attempt to calculate the molecular weight between entanglements has been made to compare the chemical structure of these PAEK. Even if the uncertainty is high due to the lack of experimental data at low frequency, we provide some information towards a better understanding of the properties of $\mathrm{AE} 250$. Lastly, the complex viscosity of $\mathrm{AE}$ 250 flakes and films is compared with other commercial PAEK such as PEEK and PEKK from data available in the literature. The viscosity and its variation with temperature are similar to those for PEKK 6002. These results confirm that the properties of new Victrex AE250 are high enough to compete with other commercially available PAEK among high performance thermoplastics. Moreover, a better control of the crystallization will be possible thanks to a slower kinetics compared to PEEK. Also, a lower melting temperature and polydispersity will facilitate the processing conditions. Still, shorter relaxation times are decisive for welding, compression molding, and additive manufacturing of polymers and composites.

As described by Victrex patent, ${ }^{43}$ the PAEK chemical structure consists of chains of two repeat units: -O-R1-OR3 and -O-R2-O-R3 with R1 selected from phenyl, terphenyl, napthyl or phenyletherphenyl moities, R2 is a biphenyl or terphenyl moities and R3 is a benzophenone or other similar benzenic compounds. We assume that the AE250 flakes are composed of more flexible moities compared to films.

\section{ACKNOWLEDGMENT}

We are grateful to Victrex company for supplying PAEK AE 250 films and flakes.

\section{ORCID}

France Chabert (10 https://orcid.org/0000-0001-6309-4372 Gerard Bernhart (1) https://orcid.org/0000-0002-1364920X

\section{REFERENCES}

[1] I. Chang, J. Lees, J. Thermoplast. Compos. Mater. 1988, 1, 277.

[2] K. K. Chawla, Composite Materials: Science and Engineering (Springer Science \& Business Media, 2012), ISBN 978-0387-74365-3, google-Books-ID: rbuNxwzM27cC. 
[3] S.-S. Yao, F.-L. Jin, K. Y. Rhee, D. Hui, S.-J. Park, Compos. Part B: Eng. 2018, 142, 241.

[4] D. J. Kemmish, J. N. Hay, Polymer 1985, 26, 905.

[5] P. Cebe, S. Y. Chung, S.-D. Hong, J. Appl. Polym. Sci. 1987, 33, 487.

[6] S. X. Lu, P. Cebe, M. Capel, Polymer 1996, 37, 2999.

[7] C.-C. M. Ma, C.-L. Lee, N.-H. Tai, Polym. Compos. 1992, $13,435$.

[8] P. R. Monich, B. Henriques, A. P. Novaes de Oliveira, J. C. M. Souza, M. C. Fredel, Mater. Lett. 2016, 185, 593.

[9] T. E. Attwood, P. C. Dawson, J. L. Freeman, L. R. J. Hoy, J. B. Rose, P. A. Staniland, Polymer 1981, 22, 1096.

[10] V. Kishore, C. Ajinjeru, C. E. Duty, A. A. O. Hassen, J. M. O. Lindahl, P. O. Liu, and V. O. Kunc, Tech. Rep., Oak Ridge National Lab. (ORNL), Oak Ridge, TN (United States) 2017

[11] K. H. Gardner, B. S. Hsiao, R. R. Matheson, B. A. Wood, Polymer 1992, 33, 2483.

[12] B. Hu, X. Duan, Z. Xing, Z. Xu, C. Du, H. Zhou, R. Chen, B. Shan, Mech. Mater. 2019, 137, 103139.

[13] M. F. Arif, S. Kumar, K. M. Varadarajan, W. J. Cantwell, Mater. Des. 2018, 146, 249.

[14] K. Friedrich, Z. Lu, A. M. Hager, Wear 1995, 190, 139.

[15] J. Audoit, L. Rivière, J. Dandurand, A. Lonjon, E. Dantras, C. Lacabanne, J. Therm. Anal. Calorim. 2018, 135, 2147.

[16] W. P. Cox, E. H. Merz, J. Polym. Sci. 1958, 28, 619.

[17] M. Day, J. D. Cooney, and D. M. Wiles, J. Anal. Appl. Pyrolysis. 1990, 40, 163.

[18] M. Day, D. Sally, D. M. Wiles, J. Appl. Polym. Sci. 1990, 40, 1615.

[19] V. Mylläri, T.-P. Ruoko, J. Vuorinen, H. Lemmetyinen, Polym. Degrad. Stab. 2015, 120, 419.

[20] K. L. White, L. Jin, N. Ferrer, M. Wong, T. Bremner, H.-J. Sue, Polym. Eng. Sci. 2013, 53, 651.

[21] A. S. Shabaev, A. A. Zhansitov, Z. I. Kurdanova, L. K. Kuchmenova, S. Y. Khashirova, Chin. J. Chromatogr. 2018, 36, 395.

[22] L. Martineau, F. Chabert, G. Bernhart, T. Djilali, ECCM 2016 Proceeding of the 17th European Conference on Composite Materials; Munich, Germany 2016, 40, p. 8.

[23] C. N. Velisaris, J. C. Seferis, Polym. Eng. Sci. 1986, 26, 1574.

[24] T. Y. Ko, E. M. Woo, Polymer 1996, 37, 1167.

[25] Z. Jiang, P. Liu, H.-J. Sue, T. Bremner, Polymer 2019, 160, 231.

[26] M. Doumeng, L. Makhlouf, F. Berthet, O. Marsan, K. Delbé, J. Denape, F. Chabert, Polym. Test. 2021, 93, 106878.

[27] L. Martineau, F. Chabert, B. Boniface, G. Bernhart, Int. J. Adhes. Adhes. 2019, 89, 82.
[28] D. S. Bangarusampath, H. Ruckdäschel, V. Altstädt, J. K. W. Sandler, D. Garray, M. S. P. Shaffer, Polymer 2009, 50, 5803.

[29] M. Garcia-Leiner, M. T. F. Reitman, M. J. El-Hibri, R. K. Roeder, Polym. Eng. Sci. 2017, 57, 955.

[30] J. Seo, D. Parisi, A. M. Gohn, A. Han, L. Song, Y. Liu, R. P. Schaake, A. M. Rhoades, R. H. Colby, Macromolecules 2020, 53, 10040.

[31] M. Day, T. Suprunchuk, J. D. Cooney, D. M. Wiles, J. Appl. Polym. Sci. 1988, 36, 1097.

[32] F. Wang, J. Roovers, P. M. Toporowski, Macromolecules 1993, $26,3826$.

[33] G. C. Berry, T. Fox, Advances in Polymer Science, Springer, Berlin, Heidelberg 1968, p. 261.

[34] S. B. Bakrani, F. Chabert, V. Nassiet, A. Cantarel, C. Garnier, AIP Conf. Proc. 1896.

[35] E. Bessard, Phd thesis, Toulouse, France 2012

[36] J.-F. Lamethe, Phd thesis, Paris, France 2004

[37] M. Coulson, L. Q. Cortés, E. Dantras, A. Lonjon, C. Lacabanne, J. Appl. Polym. Sci. 2018, 135, 46456.

[38] P. G. De Gennes, Nature 1979, 282, 367.

[39] S. Takahashi, J. Colloid Sci. 1954, 9, 313.

[40] R. G. Larson, R. G. Larson, The Structure and Rheology of Complex Fluids, Oxford University Press, Oxford, England 1999.

[41] O. Herrmann Schonherr, A. Schneller, A. M. Seifert, M. Soliman, J. H. Wendorff, Makromol. Chem. 1992, 193, 1955.

[42] J. Roovers, P. Toporowski, R. Ethier, High Perform. Polym. 1990, 2, 165.

[43] H. Glynn, L. A. Richard, P. S. Nigel, and L. John, Polymeric materials 2017

[44] T. Choupin, Phd thesis, Paris, France, 01882121(in French) 2017

[45] M. Coulson, Phd thesis, Toulouse, France 2018

[46] C. Nicodeau, Phd thesis, Paris, France 2005

\section{SUPPORTING INFORMATION}

Additional supporting information may be found online in the Supporting Information section at the end of this article. 